\title{
Activin A balance regulates epithelial invasiveness and tumorigenesis
}

\author{
Grégoire F Le Bras ${ }^{1,6}$, Holli A Loomans ${ }^{2,6}$, Chase J Taylor ${ }^{1}$, Frank L Revetta ${ }^{3,4,5}$ and Claudia D Andl ${ }^{1,2,3,4}$
}

Activin $\mathrm{A}$ (Act $\mathrm{A}$ ) is a member of the TGF $\beta$ superfamily. Act $A$ and $\operatorname{TGF} \beta$ have multiple common downstream targets and have been described to merge in their intracellular signaling cascades and function. We have previously demonstrated that coordinated loss of E-cadherin and TGF $\beta$ receptor II (T $\beta$ RII) results in epithelial cell invasion. When grown in threedimensional organotypic reconstruct cultures, esophageal keratinocytes expressing dominant-negative mutants of E-cadherin and T $\beta$ RII showed activated Smad 2 in the absence of functional T $\beta$ RII. However, we could show that increased levels of Act A secretion was able to induce Smad2 phosphorylation. Growth factor secretion can activate autocrine and paracrine signaling, which affects crosstalk between the epithelial compartment and the surrounding microenvironment. We show that treatment with the Act $A$ antagonist Follistatin or with a neutralizing Act $A$ antibody can increase cell invasion in organotypic cultures in a fibroblast- and MMP-dependent manner. Similarly, suppression of Act A with shRNA increases cell invasion and tumorigenesis in vivo. Therefore, we conclude that maintaining a delicate balance of Act $A$ expression is critical for homeostasis in the esophageal microenvironment.

Laboratory Investigation (2014) 94, 1134-1146; doi:10.1038/labinvest.2014.97; published online 28 July 2014

Activin A (Act A), like other members of the TGF $\beta$ superfamily, is a regulator of embryonic development and tumorigenesis. ${ }^{1-3}$ Act A binds to type II activin receptors, ActRII/ IIB, that have intrinsic serine/threonine kinase activity. Binding of Act A results in the recruitment of activin receptor type I, ALK4, and the subsequent phosphorylation and activation of Smad2/3 (see refs. 4,5) TGF $\beta$ and Activin signaling intersect at the level of $S \operatorname{mad} 2 / 3$ resulting in common downstream effector activation.

Previous research has shown that coordinated loss of E-cadherin and TGF $\beta$ receptor II (T $\beta$ RII) occurs in the majority of esophageal squamous cell cancers. ${ }^{6}$ Based upon this evidence, we have established an organotypic culture model system utilizing esophageal keratinocytes expressing dominant-negative mutants of E-cadherin and T $\beta$ RII to investigate the biological consequences of their loss. Keratinocytes expressing dominant-negative forms of E-cadherin and $\mathrm{T} \beta \mathrm{RII}$ and tumor tissues with coordinated loss of E-cadherin and T $\beta$ RII retained the expression of phosphorylated Smad2, thus suggesting that Act A compensates for the loss of TGF $\beta$ signaling and induces the activation of Smad2.
Similar to TGF $\beta$, Act A is described as having pro- and anti-tumorigenic functions. Members of the TGF $\beta$ family, including Act A, can downregulate E-cadherin promoting cell invasion. ${ }^{7}$ Our previous study showed increased cell invasion in Boyden chamber assays in response to Act A stimulation through an E-cadherin-dependent increase of the CD44 variant form in the esophageal cancer cell line TE11 (ref. 8). In the current study, we further demonstrate the increased secretion of Act A in invasive organotypic cultures. Act A can suppress proliferation in different tumor cells, ${ }^{9-11}$ mainly through the induction of p15INK4B, ${ }^{12}$ whereas others describe an oncogenic role for Act A. ${ }^{3,13-16}$ From these reports and similar observations made for TGF $\beta 1$, which also has been shown to have dual functions, ${ }^{17,18}$ Act $\mathrm{A}$ is likely to have a role in the regulation of epithelial homeostasis. Interestingly, other studies demonstrated that Act A is necessary for the maintenance of self-renewal in human embryonic stem cells through the induction of Oct4, Nanog, Nodal, Wnt3, FGF-2 and by suppressing BMP signaling. ${ }^{19}$ These observations illustrate Act A function as a mediator of stemness with the potential for being a cancer stem cell

\footnotetext{
${ }^{1}$ Department of Surgery, Vanderbilt University Medical Center, Nashville, TN, USA; ${ }^{2}$ Department of Cancer Biology, Vanderbilt University Medical Center, Nashville, TN USA; ${ }^{3}$ Vanderbilt Ingram Cancer Center, Vanderbilt University Medical Center, Nashville, TN, USA; ${ }^{4}$ Vanderbilt Digestive Disease Center, Vanderbilt University Medical Center, Nashville, TN, USA and ${ }^{5}$ Department of Pathology, Vanderbilt University Medical Center, Nashville, TN, USA

Correspondence: $\operatorname{Dr}$ CD Andl, PhD, Department of Surgery and Cancer Biology, Vanderbilt University Medical Center, 2213 Garland Avenue, 10445 MRB IV, Nashville, TN 37232, USA.

E-mail: claudia.andl@vanderbilt.edu

${ }^{6}$ These authors contributed equally to this work.

Received 21 April 2014; revised 3 June 2014; accepted 23 June 2014
} 
marker. ${ }^{20,21}$ Furthermore, suppression of Id2, a downstream target of Act A and TGF $\beta 1$, is central to the induction of epithelial-mesenchymal transition, ${ }^{22}$ a mechanism known to induce single-cell invasion, which is antagonized by BMP. Another Act A target, Id1, regulates epidermal homeostasis. ${ }^{23}$ However, the role of Id 1 in proliferation could only be demonstrated in three-dimensional cultures, not in monolayer experiments. ${ }^{23}$

To better understand the complex role of Act A in esophageal cell invasion, we employed three-dimensional organotypic cultures to reconstitute the epithelium with squamous esophageal epithelial cells expressing wild-type full-length E-cadherin, dominant-negative mutant E-cadherin, or dominant-negative mutant $\mathrm{E}$-cadherin and TGF $\beta$ receptor II (ECdnT). We found that Act A secretion is increased in ECdnT cells. In addition, altered cell invasion of ECdnT cell in vitro was dependent upon fibroblasts and MMP activation. In vivo, we show that loss of Act A can initiate tumorigenesis using xenograft models. Overall, our data indicate that Act A concentrations contribute to the homeostasis in the esophageal microenvironment and in the absence of functional TGF $\beta$ signaling can shift the balance toward tumor invasiveness.

\section{MATERIALS AND METHODS \\ Cell Culture and Tissues}

Primary esophageal epithelial cells (keratinocytes) from normal human esophagus were established as described previously. ${ }^{6}$ Fetal esophageal fibroblasts (FEF) were isolated as previously described ${ }^{6}$ and head and neck cancer-associated fibroblasts (CAF) were purchased from Asterand (Detroit, MI). Fibroblasts were grown in DMEM with $5 \%$ fetal bovine serum (FBS, Hyclone, Thermo Fisher Scientific, Waltham, MA), $100 \mathrm{U} / \mathrm{ml}$ penicillin, and $100 \mu \mathrm{g} / \mathrm{ml}$ streptomycin (Gibco, Invitrogen, Carlsbad, CA). HUVEC cells were grown in EBM-2 basal media (Lonza Biosciences, Walkersville, MD) supplemented with endothelial growth medium 2 (EGM-2) growth factors (Lonza Biosciences).

A tissue microarray with 83 spotted squamous esophageal tissues, AccuMax Tissue Microarray, was purchased from ISU Abxis (distributed by Accurate Chem, Westbury, NY).

\section{Lentivirus Infection}

shRNA-mediated loss of Act A in esophageal squamous cells was performed using shRNA directed toward three different target sequences. Act A shRNA and control pGIPZ plasmids were purchased from Thermo Scientific. Virus was generated using HEK293T cells. Cells were then transduced and sorted using flow cytometry before experimental use.

\section{Xenograft Animal Experiments}

The current study protocol was reviewed and approved by the Vanderbilt University Animal Care and Use Committee. Briefly, a total of $1 \times 10^{6}$ cells (INHBA high and normal esophageal fibroblasts) were suspended in $150 \mu \mathrm{l}$ of Matrigel
(BD Bioscience, Franklin Lakes, NJ) and kept on ice before subcutaneous injection into the flanks of $8-10$-week-old female NOD/SCID mice (The Jackson Laboratory, Bar Harbor, ME). Tumor growth was monitored weekly by caliper measurements.

\section{Organotypic Culture}

Organotypic reconstructs were grown as previously described ${ }^{6}$ with the exception that each culture was rinsed in $1 \times$ PBS and incubated with epidermalization 3 medium lacking serum for 2 more days before harvesting. The following treatments were added to the organotypic cultures at the time of epithelial seeding and renewed with every media change: A quantity of $5 \mathrm{ng} / \mathrm{ml}$ recombinant human TGF $\beta 1$, $10 \mathrm{ng} / \mathrm{ml}$ Act A, $100 \mathrm{ng} / \mathrm{ml}$ Follistatin, and $600 \mathrm{ng} / \mathrm{ml}$ neutralizing antibody (nAb) against Act A (all from R\&D Systems), or $1 \mu \mathrm{M}$ A83-01 (Tocris, Bristol, UK) and $1 \mu \mathrm{M}$ GM6001 (Millipore EMD, Billerica, MA). Puromycin treatment at $5 \mu \mathrm{g} / \mathrm{ml}$ on day 5 was applied to induce fibroblast cell death. The culture matrix was washed serially with PBS, before the epithelial cells were seeded.

\section{Spheroid Formation}

Spheroid assays were performed as described previously. ${ }^{6}$ In brief, cells were resuspended in $2 \%$ Matrigel and then cultured on a Matrigel layer in chamber slides (Nalge Nunc, Naperville, IL). Cells were fixed in $4 \%$ paraformaldehyde (Fisher Scientific, Hampton, NJ) overnight at $4{ }^{\circ} \mathrm{C}$. Incubation with Alexa568-conjugated phalloidin was overnight at $4{ }^{\circ} \mathrm{C}$.

\section{Proliferation Assays}

Cells were plated at 500 cells per well in a 96-well plate for proliferation assays. WST-1 reagent (Roche, Nutley, NJ) was added to each well at the time points indicated and incubated at $37^{\circ} \mathrm{C}$ for a minimum of $1 \mathrm{~h}$. Absorbance measurements at $450 \mathrm{~nm}$ were taken using a BioTek Synergy 4-plate reader (Winooski, VT). Measurements were taken in 24-hour increments.

\section{Immunofluorescence}

Organotypic culture tissue, previously fixed in formalin for $24 \mathrm{~h}$ and embedded in paraffin, was sectioned at $5 \mu \mathrm{m}$, deparaffinized, and heated in $1 \times \mathrm{TE}$ buffer in a pressure cooker for $12 \mathrm{~min}$ for antigen retrieval. Samples were blocked in $1 \times$ PBS with $5 \%$ bovine serum albumin (Sigma-Aldrich, St Louis, MO) for $1 \mathrm{~h}$ before incubation with primary antibody in $1 \times$ PBS BSA $5 \%$ overnight at $4{ }^{\circ} \mathrm{C}$. Tissues were then rinsed three times in PBS and incubated with secondary antibodies in $1 \times$ PBS BSA $5 \%$ for $1 \mathrm{~h}$ at room temperature. After additional rinses with PBS, the sections were mounted with Vectashield mounting medium containing DAPI (Vector Laboratories, Burlingame, CA). Images were taken on a Zeiss microscope, using Axiocam and Axiovision software (Carl Zeiss Microscopy, Thornwood, NY). 
Immunohistochemistry for $\mathrm{T} \beta \mathrm{RII}$ and $\mathrm{pSmad} 2$ in the tissue microarrays and OTC samples was done using the Vectastain Elite kit (Vector Laboratories) following the manufacturer's protocol.

\section{Western Blot}

Western blots were performed as previously described. ${ }^{8}$ The results are representative of at least three independent experiments.

\section{Flow Cytometry}

Flow cytometry was used to separate lentivirus-transduced from the non-transduced population based upon GFP + status. Gates were set to divide high and low GFP + expressing cells. Flow cytometry experiments were performed using a BD ArialII flow cytometer (BD Biosciences) in the VUMC Flow Cytometry Shared Resource. After sorting, the cells were returned to culture for future experiments.

\section{ELISA}

Capture ELISAs for Act A and TGF $\beta 1$ were purchased from $\mathrm{R} \& \mathrm{D}$ Systems. The protocols were performed according to the manufacturers' instructions.

\section{Invasion Assays}

Matrigel-based invasion chamber assays were purchased from BD Biosciences and performed according to manufacturer's direction. Act A was added either to the top insert or the bottom chamber to assess hapto- versus chemotactic invasion during $16-24 \mathrm{~h}$ incubation.

For transendothelial invasion assays (XCELLigence system, Roche Diagnostics), Roche E-plates (Roche Diagnostics) were treated with $100 \mu \mathrm{l}$ of $0.1 \%$ sterile gelatin (SigmaAldrich) overnight at $4{ }^{\circ} \mathrm{C}$. Plates were washed once with sterile PBS before the addition of HUVEC cells (Lonza Biosciences). A quantity of 25000 HUVEC cells $/ 100 \mu$ l were seeded on E-plates and incubated for $18 \mathrm{~h}$ at $37^{\circ} \mathrm{C}$. The cell index was monitored on the xCELLigence system while the monolayer was formed. Following the formation of the HUVEC monolayer, which is indicated by the plateau in the cell index, the endothelial cell growth medium EGM-2 was removed and $100 \mu \mathrm{l}$ of RPMI containing 5\% serum media was added. The cell index was monitored for $4 \mathrm{~h}$ and allowed to stabilize. Then, esophageal epithelial cells pretreated with Act A for $24 \mathrm{~h}$ were added to each well at a density of 5000 cells $/ 100 \mu$ l. The cell index was normalized to the HUVEC monolayer and invasion was monitored over time as epithelial cells disrupt the endothelial cell layer (changes in initial slope). Rate of invasion of the cell lines were calculated in real time according to the RTCA software version 1.2.

\section{Zymography}

Zymography was performed as previously described. ${ }^{8}$ Briefly, conditioned medium was separated by SDS-PAGE at $4{ }^{\circ} \mathrm{C}$ in gel containing gelatin. The gels were then washed in Triton
$2.5 \%(\mathrm{v} / \mathrm{v})$ in $\mathrm{ddH}_{2} \mathrm{O}$ twice for $30 \mathrm{~min}$ and incubated overnight in at $37^{\circ} \mathrm{C}$ in a development buffer $(0.05 \mathrm{M}$ Tris- $\left.\mathrm{HCl} \mathrm{pH} 8.8,5 \mathrm{mM} \mathrm{CaCl}_{2}, 0.02 \% \mathrm{NaN}_{3}\right)$. Then, the gels were stained in $0.1 \%$ Coomassie Blue R-250 for an hour and destained in methanol/acetic/acid/water solution (10\%:20\%:70\%, v-v:v). Images were taken on Gel Doc XR system (Bio-Rad, Hercules, CA).

\section{Antibodies and Other Reagents}

Alexa568-conjugated Phalloidin (Invitrogen), aSMA (SigmaAldrich) and Podoplanin (eBioscience, San Diego, CA) were used for immunofluorescence. Anti-T $\beta$ RII (clone L21) and PAI-1 (Santa Cruz Biotechnologies, Santa Cruz, CA), Ki67 (Vector Laboratories). and phospho-Smad2 (Cell Signaling, Danvers, MA) were used for immunohistochemistry. Antibodies used to detect protein by western blotting were E-cadherin (BD Transduction, Franklin Lakes, NJ), vimentin (Sigma-Aldrich); total Smad 2, phospho-Smad2, were purchased from Cell Signaling Technologies; Alpha-tubulin from Abcam (Cambridge, MA).

\section{Data Set Analysis}

Datasets made publicly available from Oncomine (http:// www.nextbio.com/b/nextbio.nb), GEO Data sets (http:// www.ncbi.nlm.nih.gov/gds/24 and NextBio (http://www. nextbio.com/b/nextbio.nb ${ }^{25}$ ) were used to query clinical correlations with Act A (Supplementary Table 1). The collected information from each data set was analyzed and visualized in Prism version 6.00 for Mac (GraphPad software, La Jolla, CA, http://www.graphpad.com).

\section{Biostatical Analysis}

Biostatistical was performed using Prism version 6.00 for Mac. In vitro and in vivo experiments were analyzed using Student's $t$-tests or one-way ANOVAs. Statistical significance was set at $P<0.05$. All experiments were done in triplicates with at least three biological replicates.

\section{RESULTS \\ Increased Epithelial Cell Invasion is Associated with Increased Act A Secretion}

The R-Smads (Smad2 and Smad3) are common downstream mediators of both TGF $\beta$ and Activin signaling. We performed immunohistochemistry using antibodies against T $\beta$ RII and $\mathrm{pSmad} 2$ to determine their expression in noninvasive and invasive organotypic cultures. Keratinocytes expressing wildtype E-cadherin (E) form a non-invasive epithelial sheet, while expression of dominant-negative E-cadherin (EC) or combined expression of dominant-negative E-cadherin and T $\beta$ RII (ECdnT) leads to a gradual increase of invasiveness as shown previously. ${ }^{8}$ We have previously shown that expression of dominant-negative E-cadherin correlates with lower T $\beta$ RII levels in EC cells, potentially due to a lack of its stabilization at the cell membrane. ${ }^{6}$ Even though the signal for $\mathrm{T} \beta \mathrm{RII}$ was lower in EC and ECdnT cells than in the 

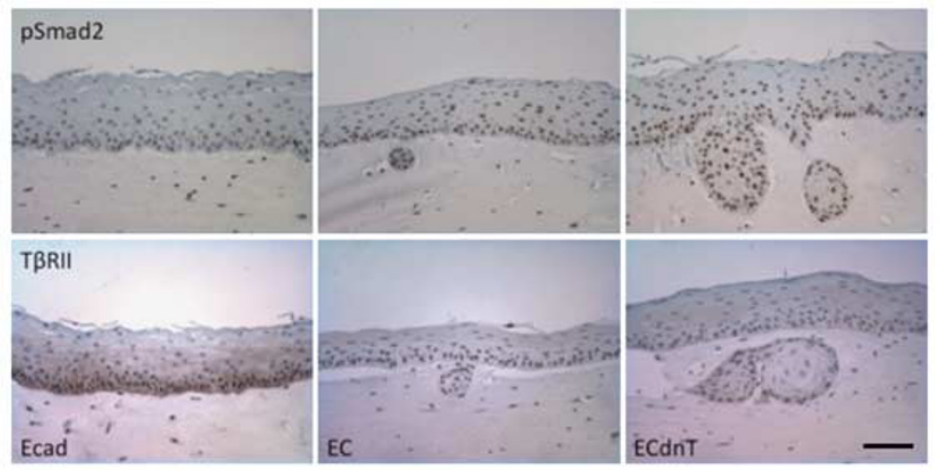

b

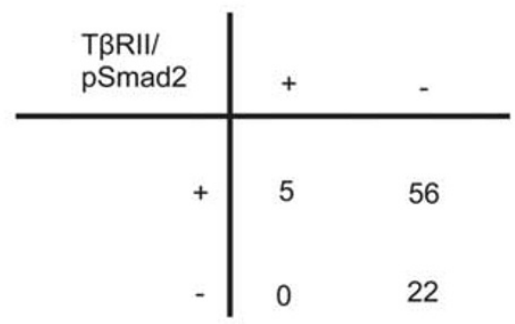

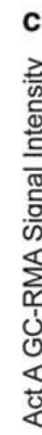

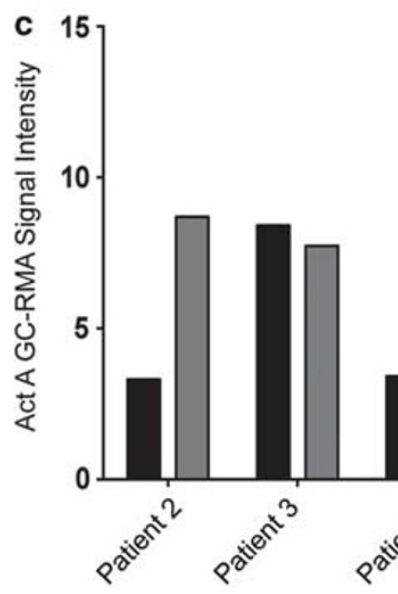

d

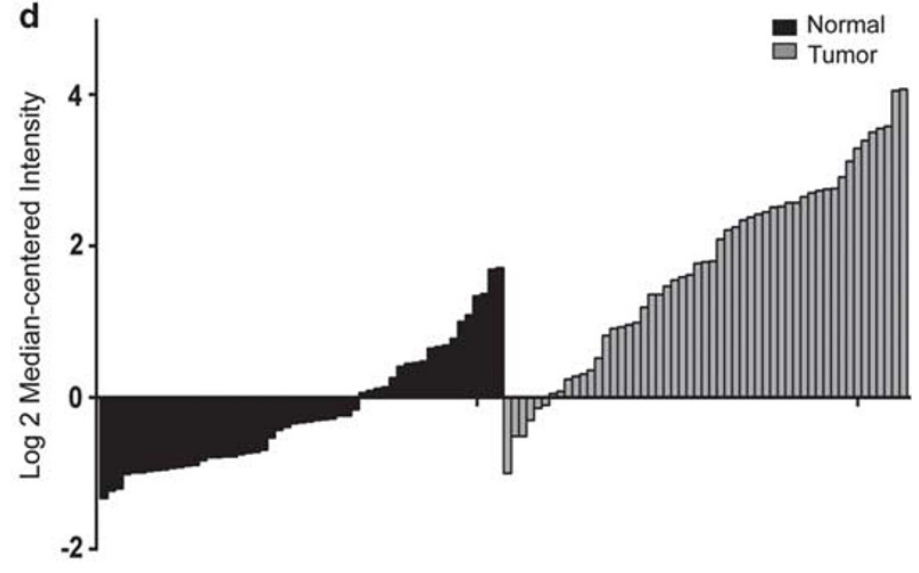

Figure 1 Activin A (Act A) specifically stimulates phosphorylation of Smad2 and Act A upregulation is common in esophageal squamous cell carcinoma (ESCC). (a) Immunohistochemistry staining with antibody against phosphorylated Smad2 (pSmad2) and TGF $\beta$ receptor II (T $\beta$ RII) showed increased nuclear signal for pSmad2 in the invasive dominant-negative E-cadherin and T $\beta$ RII (ECdnT) organotypic cultures. Scale bar, $50 \mu \mathrm{m}$. (b) Analysis of immunohistochemistry staining for T $\beta$ RII and pSmad2 in 83 ESCC cases in a tissue microarray shows no significant correlation. Fisher's exact test, two tailed $P=0.3182$. (c) Five paired normal adjacent and ESCC tissues (GSE17531) were analyzed for INHBA mRNA expression, which identified upregulation of INHBA in four ESCC samples. (d) Waterfall plot of a publically available data set (GSE23400) represented upregulation of INHBA in the ESCC (gray bars) samples versus normal (black bars).

normal control epithelium, represented by the $\mathrm{E}$ cells (Figure 1a), we observed a strong signal of nuclear pSmad2 in invasive ECdnT cells. Nuclear localization of pSmad2 in the absence of T $\beta$ RII staining supports the notion that Smad2 can be activated and phosphorylated through a separate signaling pathway, when T $\beta$ RII expression is low or disrupted. We subsequently analyzed 83 esophageal squamous cell carcinoma (ESCC) tissues for E-cadherin, ${ }^{6}$ $\mathrm{T} \beta \mathrm{RII}$ and pSmad2 expression. Seventy-one percent of the tumor tissues retained Smad2 activation in the absence of T $\beta$ RII (Figure 1b). To determine the levels of Act A gene expression in ESCC, we analyzed published data sets and identified upregulation of Act A in ESCC tumor samples compared with normal tissues (Figure 1c and d; Supplementary Table $1^{26,27}$ ).

As esophageal epithelial cells invade in a fibroblastdependent manner, ${ }^{6,8}$ we employed organotypic cultures comparing the effects of the presence of embedded FEF and CAF on cell invasion and Act A secretion (Figure 2a and b). $\mathrm{E}$ or EC cells grown in organotypic cultures with FEFs or
CAFs had minimal invasive potential, whereas ECdnT cells showed cell invasion in either context (Figure 2a). Immunofluorescence staining with antibodies against the fibroblastspecific marker $\alpha$ SMA (green) exclusively labeled FEFs and CAFs in the matrix, while Podoplanin (red) expression, a putative marker of collective invasion, stained the basal membrane of the epithelial cells (Figure 2a).

As our analysis of human SCC samples implicated Act A in the regulation of Smad2 and cell invasion (Figure 1), we determined the levels of Act $\mathrm{A}$ in the conditioned media from organotypic cultures with different levels of invasion. We performed ELISA and observed a positive association between Act A secretion levels and epithelial cell invasion (Figure 2b). To test for specificity of Act A-mediated phosphorylation of Smad2 in this model system, we isolated protein from keratinocytes grown in a monolayer on plastic for western blot analysis. We compared protein lysates from conditions with Act A stimulation or nAb to demonstrate that phosphorylation of Smad2 could be induced by Act A with high specificity. Increased signal for $\mathrm{pSmad} 2$ was 
a

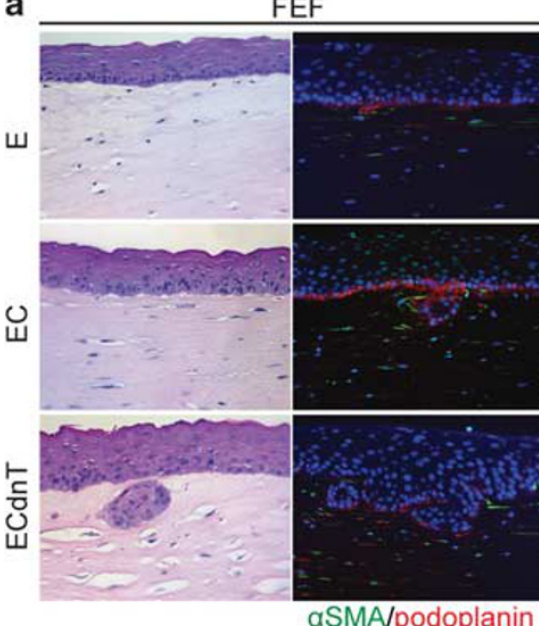

aSMA/podoplanin
CAF

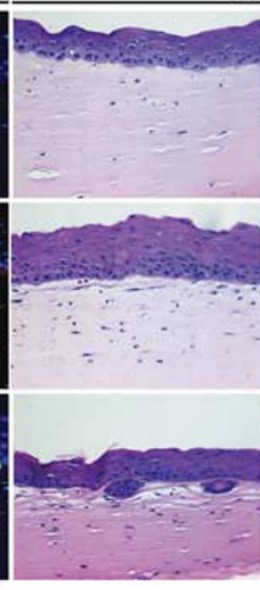

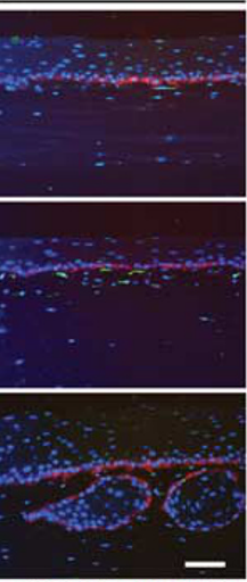

aSMA/podoplanin b

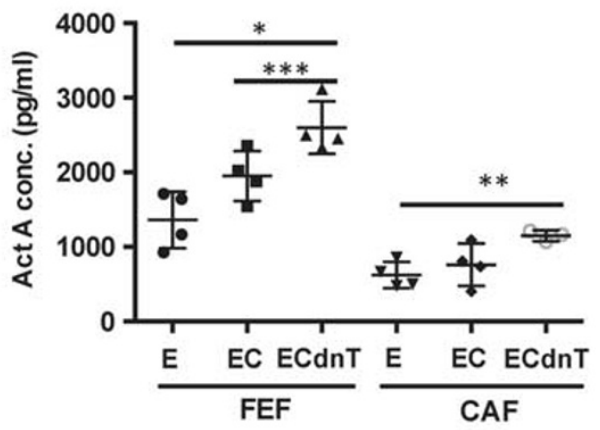

C

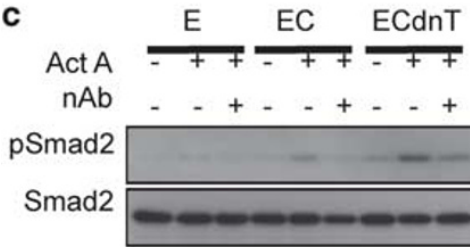

ECdnT

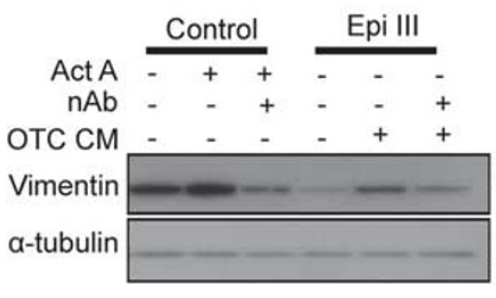

d

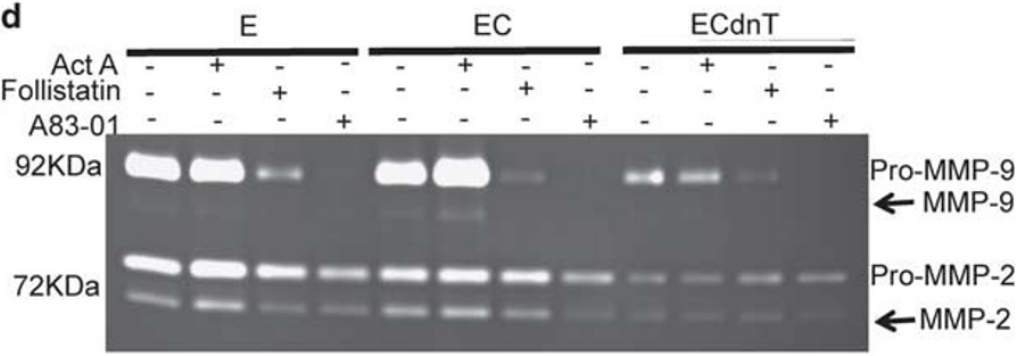

Figure 2 Increased epithelial cell invasion is associated with higher levels of secreted Activin A (Act A). (a) Esophageal epithelial cells expressing wildtype full-length E-cadherin (E), dominant-negative mutant E-cadherin (EC) or dominant-negative mutant E-cadherin and TGF $\beta$ receptor II (ECdnT) were grown in organotypic cultures with either fetal esophageal fibroblasts (FEF) or cancer-associated fibroblasts (CAF) embedded in the underlying matrix. Immunofluorescence staining with antibody against $\alpha$ SMA (green) and podoplanin (red) showed similar expression pattern in the cultures. Scale bar, $50 \mu \mathrm{m}$. (b) Act A concentration in conditioned media from organotypic cultures is higher in invasive cultures as measured using indirect ELISA. ${ }^{*} P=0.003,{ }^{*} P=0.005,{ }^{* *} P=0.03$ (c) Stimulation of epithelial cells with Act A in monolayer plastic culture demonstrated phosphorylation of Smad. Neutralizing antibody $(\mathrm{nAb})$ against Activin prevented the induction of pSmad2 by Act A. Following stimulation with Act A or with conditioned media from organotypic culture increased expression of vimentin was detected after $48 \mathrm{~h}$ by western blot. The increase was reversed in the presence of $\mathrm{nAb}$. (d) Inhibition with the Act A antagonist, Follistatin, or a pan-TGF $\beta$ inhibitor A83-01 suppressed MMP-9 secretion in E, EC, and ECdnT cells as measured by gelatin zymography. Upper bands reflect pro-MMP, lower bands activated, cleaved MMP (arrow).

detected following Act A stimulation, which was reduced in the presence of the nAb. Similarly, treating ECdnT cells with Act A or conditioned media from organotypic cultures induced vimentin, a mesenchymal cytoskeleton component and a marker of tumor cell invasion. Conversely, Act A-nAb inhibited vimentin expression (Figure 2c).

We speculated that Act A may alter extracellular matrix degradation, as epithelial cell invasion is strongly associated with the digestion of the extracellular matrix by matrix metalloproteases. Therefore, we collected conditioned media from cells grown on monolayer and analyzed the secretion of the collagen-digesting matrix metalloproteases MMP-9 and
MMP-2 using gelatin zymography (Figure 2d). When using recombinant Follistatin, the endogenous inhibitor of Act $A, 28$ or A83-01 (an inhibitor for ALK4, 5 and 7), MMP-9 secretion was reduced compared with untreated or Act A-stimulated monolayer cultures (Figure 2d).

\section{Stimulation with Act A Increases Spheroid Size and Cell Invasion In Vitro}

To identify the functional consequences of Act A-mediated Smad2 signaling, we grew E, EC, and ECdnT cells embedded in Matrigel to induce spheroid formation (Figure 3a). In the presence of Act A, ECdnT cells form more and larger 

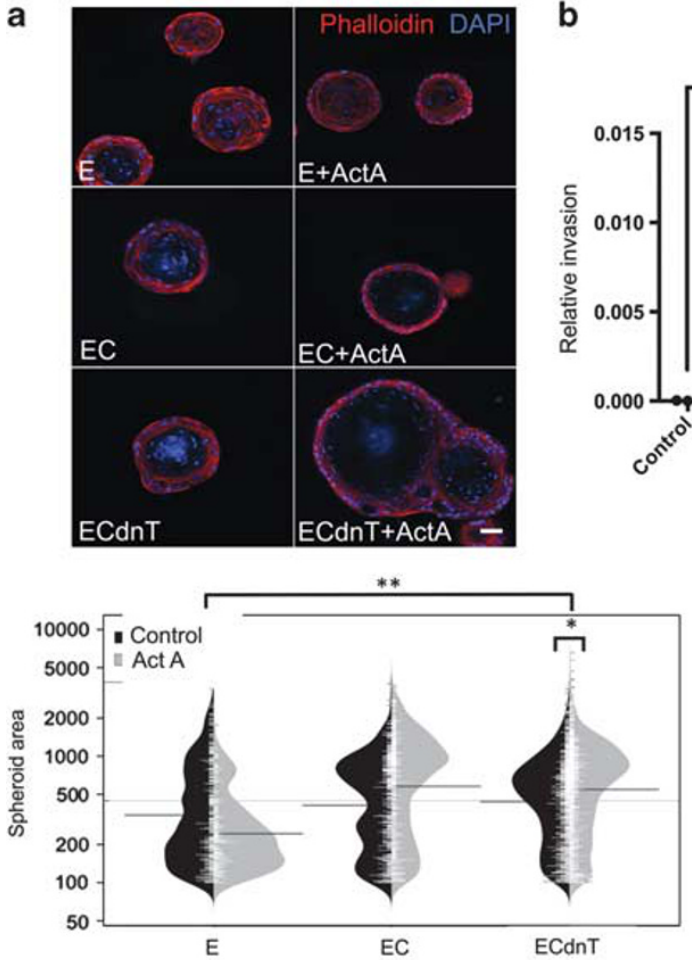

b

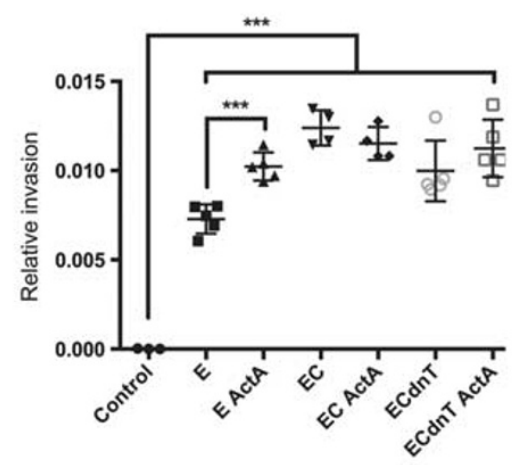

d
C

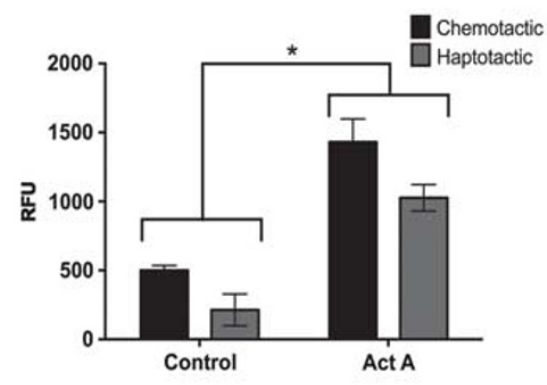

Figure 3 Stimulation with Activin A (Act A) increases spheroid size and cell invasion in vitro. (a) Esophageal epithelial cells, when grown embedded in $2 \%$ Matrigel, form spheroids. Immunofluorescence with Alexa568-conjugated Phalloidin stained the actin cytoskeleton, DAPI, blue, was used as a counterstain for nuclei. Scale bar, $50 \mu \mathrm{m}$. Stimulation with recombinant Act A increased spheroid size and number as quantified in the graph, * and ${ }^{* *} P<0.0001$. (b) Transendothelial cell migration was measured after stimulation of esophageal epithelial cells with Act $A,{ }^{* * *} P<0.0001$. (c) Haptotactic (stimulation in top chamber) and chemotactic (addition to the media in the bottom chamber) invasion of ECdnT cells in response to Act A was measured in Boyden chamber assays kSFM is media only control, ${ }^{*} P<0.0001$. (d) Proliferation index was determined after stimulation with two concentrations of Act A using the WST assay. Cell proliferation was unchanged by stimulation with Act A.

spheroids compared with E and EC cells (Graph and Supplementary Table 2). In a transendothelial invasion assay (Figure 3b), we observed decreased impedance as a measure of cell invasion through the endothelial cell layer. Epithelial cells pretreated with Act A were seeded on a layer of endothelial cells (HUVEC) and a significant disruption of the HUVEC layer was observed with Act A stimulation in normal E cells. More invasive EC and ECdnT cells disrupted the HUVEC layer to a comparable degree without or with Act A stimulation.

When assessing Act A function in Boyden chamber invasion assays (Figure 3c), we added Act A either to the top chamber as a stimulant for the ECdnT cells or to the bottom as a chemoattractant. Act A increased haptotactic as well as chemotactic cell invasion. This observation was in line with our previous report that Act A increased cell invasion in esophageal cancer cell lines. ${ }^{8}$

Finally, we show that the increased cell invasion is independent of cell proliferation, as WST-1 assays did not show differences in proliferation index in response to two different concentrations of Act A stimulation compared to untreated normal media (Figure 3d).

\section{Imbalance of Act A Induces Epithelial Cell Invasion}

Organotypic cultures allow us to measure the effects of the stromal compartment and epithelial cell homeostasis in a physiologically relevant context, while modifying signaling activation (Figure 4). As described earlier wild-type E-cadherin-expressing cells grow as a normal stratified epithelium without invasion into the matrix (Figure 4a). When treated with Act A, epithelium formation of $E$ cells remained unchanged (Figure 4a). However, the addition of Follistatin induced cell invasion, whereas Act A-nAb did not. Similarly, EC cells, which have minimal invasive potential, show slightly increased invasion when treated with Follistatin. However, Act A treatment or addition of the neutralizing Act A antibody prevented EC cell invasion. This strongly supports our idea that the cells are sensitive to changes in Act A and show differential responses when exposed to varying Act A concentrations in a context-dependent manner.

ECdnT cells have the highest potential for cell invasion and could be considered dysplastic or premalignant, ${ }^{8}$ (unpublished data). In contrast to $\mathrm{E}$ and $\mathrm{EC}$ cells, treatment with Act A did not inhibit ECdnT cell invasion. Conditions that disrupt Act A function, such as Follistatin treatment or 
a

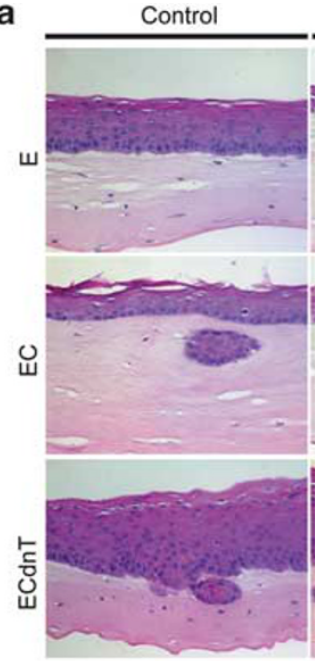

b

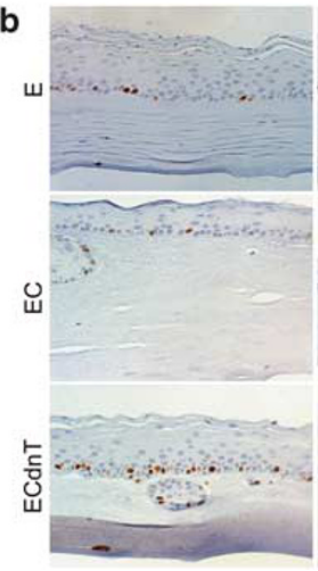

+ Act A

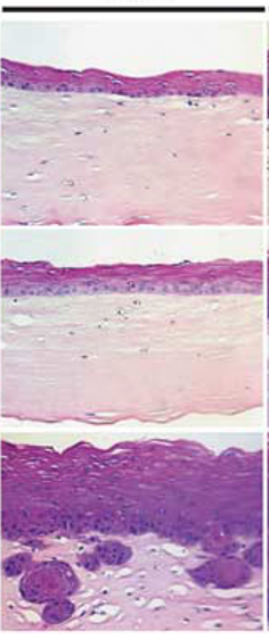

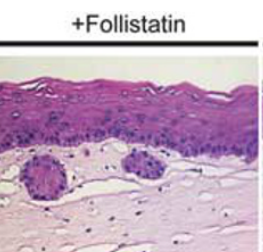

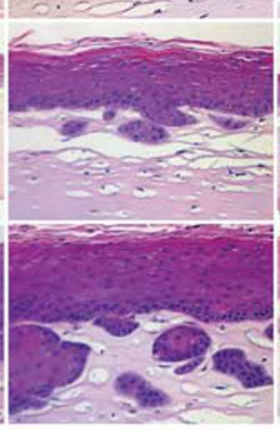

H\&E

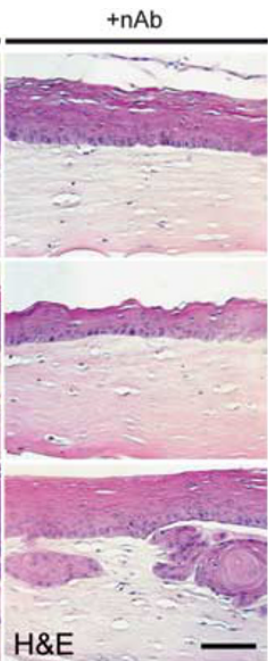

c

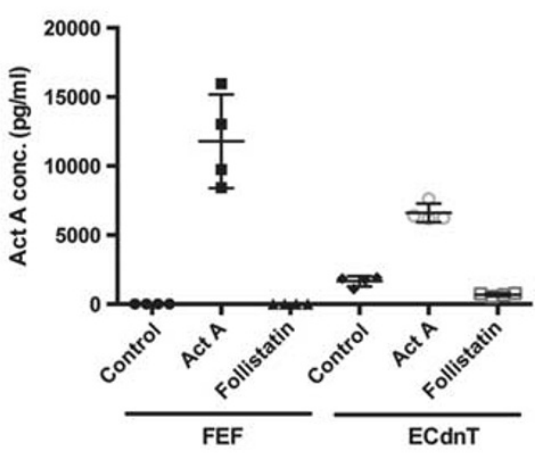

d

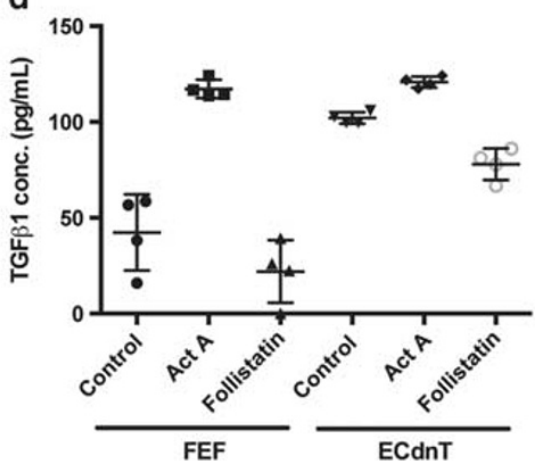

Figure 4 Imbalance of Activin A (Act A) induces epithelial cell invasion. (a) Esophageal epithelial cells expressing wild-type full-length E-cadherin (E), dominant-negative mutant E-cadherin (EC) or dominant-negative mutant E-cadherin and TGF $\beta$ receptor II (ECdnT) were grown in organotypic cultures in the presence of recombinant Act $A$, its antagonist Follistatin or a neutralizing antibody (nAb) against Act A; H\&E staining. Stimulation with Act A inhibited invasion of $E$ and EC cells, but failed to suppress ECdnT cell invasion. Follistatin increased cell invasion in all cell types, whereas the nAb prevented invasion of E and EC cells, without an effect on ECdnT cells. (b) Immunohistochemistry staining with ki67-antibody showed no differences in cell proliferation. Scale bars, $50 \mu \mathrm{m}$. (c) Indirect ELISA with antibody against Act A measured increased levels after addition of recombinant Act A in fetal esophageal fibroblasts (FEF) and ECdnT. Untreated ECdnT cells (Control) secreted higher baseline levels of Act A than FEF, which were reduced by Follistatin. (d) TGF $\beta 1$ concentration was increased in response to stimulation with Act A and overall baseline secretion was higher in control ECdnT cells than fibroblasts as measured by indirect ELISA. Follistatin inhibited TGF $\beta 1$ secretion.

Act A-nAb, enhanced ECdnT cell invasion. Although the degree of cell invasion varied between the cell lines and treatment, the proliferation index as analyzed by staining for Ki67-positive cells was unchanged (Figure 4b). Again, invasion and changes in Act A signaling were not dependent on cell proliferation. However, as disruption of Act A signaling using Follistatin or the neutralizing Act A antibody had differential effects, the balance of Act A signaling appeared to be integral for the induction of cell invasion.

In organotypic cultures, the respective treatments affected stromal as well as epithelial compartments. To analyze the role of Act A in autocrine and paracrine signaling, we determined Act A secretion levels in conditioned media from fibroblast and epithelial monolayer cultures stimulated with Act A or treated with the inhibitor Follistatin (Figure 4c). FEFs did not secrete Act A, but exogenous addition of Act A could be detected by ELISA. Follistatin treatment had no effect on fibroblasts. Act A levels in ECdnTs indicate endogenous expression and secretion, which was reduced in the presence of Follistatin. Treatment with recombinant Act A elevated the levels measured by ELISA. Interestingly, TGF $\beta 1$ levels were influenced by Act A treatment in a similar pattern. Endogenous TGF $\beta 1$ secretion was at a detectable level in fibroblasts, albeit higher in ECdnTs. Follistatin reduced TGF $\beta 1$ secretion in both cell types. This may indicate a feedback mechanism of Act A and TGF $\beta$ signaling. 


\section{Induction of Cell Invasion by Act A is Fibroblast- and MMP-Dependent}

Epithelial cells grown in a monolayer on plastic have different gene expression patterns and behaviors compared with cells grown in a physiological context such as three-dimensional organotypic cultures. We have previously shown that fibroblast-secreted factors are necessary to induce cell invasion of ECdnT cells, ${ }^{8}$ yet we observed that Act A could initiate ECdnT invasion in Boyden chamber assays in the absence of fibroblasts or fibroblast-conditioned media (Figures $3 \mathrm{~b}$ and $\mathrm{c}$ ). We aimed to create an environment to address epithelial-fibroblast crosstalk and its effects on cell invasion. First, we overlayed the cellular matrix with a collagen I layer to prevent direct physical interaction of the epithelial cells with the embedded fibroblasts and potentially minimizing access to fibroblast- secreted factors (Figure 5a). ECdnT cells did not invade into the stroma in the presence of a collagen I layer, regardless if stimulated with Act A or not. As the collagen I layer could alter the pliability and stiffness of the matrix affecting cell invasion, we next performed the experiment without the collagen I layer, however, treated the stromal layer with puromycin to kill the embedded fibroblasts. Fibroblasts were allowed to cross-link and contract the collagen/Matrigel matrix during the initial 5 days of culture. Then, fibroblasts were killed by puromycin treatment. ECdnT cells in the absence of fibroblasts did not invade into the extracellular matrix in control or Act A-stimulated cultures (Figure 5a). This supports our previous observation that fibroblast paracrine signaling is important for epithelial cell invasion.
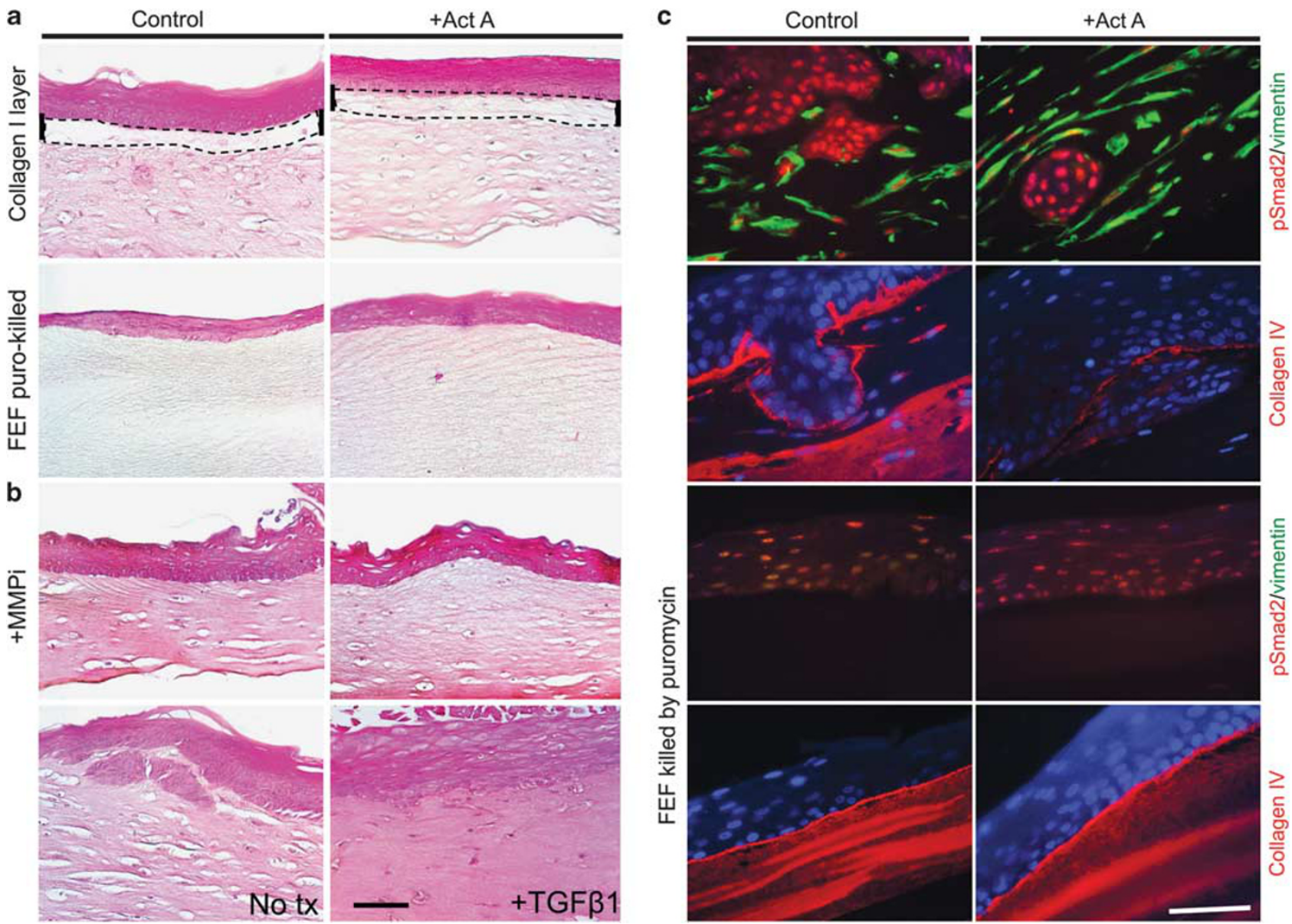

Figure 5 Regulation of cell invasion by Activin A (Act A) is fibroblast and MMP dependent. (a) Separating the cellular matrix and epithelium of the organotypic cultures growing ECdnT cells through a collagen I layer, dashed lines, prevented cell invasion in the absence (control) and presence of Act A ( + Act A). When the cellular matrix of the organotypic culture was treated with puromycin to kill the embedded fibroblasts before the ECdnT cells were seeded, epithelial formation occurred but invasion was inhibited with and without Act A stimulation. (b) Treatment of ECdnT organotypic cultures with a pan-MMP inhibitor, GM6001, suppressed cell invasion, which was not restored in the presence of Act A. Untreated (no tx) control ECdnT cells in organotypic culture invaded into the underlying matrix. TGF $\beta 1$ treatment inhibited epithelial cell invasion. Scale bars, are $50 \mu \mathrm{m}$. (c) Immunohistochemistry showed nuclear localization of phosphorylated Smad (pSmad2, red) in control and Act A-stimulated conditions. Collagen IV, red, was disrupted in invasive cultures after Act A treatment. Loss of the fetal esophageal fibroblasts (FEF), labeled green with antibody against vimentin (no staining in the lower panels), had no effect on the nuclear localization of pSmad2. The collagen IV layer was not disrupted in noninvasive cultures in the absence of FEFs. 
As MMP-9 secretion was induced by Act A treatment and correlated with increased cell invasion of ECdnT cells in organotypic cultures, we set out to determine if MMPs are necessary for Act A-induced ECdnT cell invasion. Using a pan-MMP activity inhibitor GM6001, we could abolish ECdnT cell invasion, which could not be restored by Act A addition (Figure $5 \mathrm{~b}$ ). This finding indicates that blocking MMP activity downstream of Act A disrupts the signaling cascade necessary for ECdnT cell invasion. As a control, we treated ECdnT cells with TGF $\beta 1$, which inhibited ECdnT cell invasion (Figure $5 \mathrm{~b}$ ). These data show that Act $\mathrm{A}$ and TGF $\beta 1$ have independent functions in this cell system, but also highlight the complexity of their balance. Immunofluorescence staining with antibodies against $\mathrm{pSmad} 2$ showed a strong nuclear signal in untreated control and Act A-stimulated-organotypic cultures (Figure 5c). Collagen IV (red) is deposited at the basement membrane, but is disrupted after Act A treatment. The collagen IV layer is not disturbed in noninvasive conditions without fibroblasts regardless of Act A stimulation. Absence of fibroblasts (lack of vimentinpositive cells, green), while inhibiting cell invasion, only marginally diminished pSmad2-positive signal in the epithelial layer.

\section{Act A Knockdown Results in Cell Invasion and Tumorigenesis}

Our data obtained in monolayer and OTC cultures thus far suggest that the pro-invasive role of Act A is in part driven by the presence of fibroblasts and the induction of MMP expression. Therefore, we next set out to determine if ECdnT cells would exhibit an invasive phenotype without Act A secretion and signaling. To answer this question, ECdnT cells were transduced with three distinct clones to stably express shRNA specifically targeting Act A, shINHBA. Following transduction, the cells were sorted by flow cytometry to select for GFP-positive populations. To examine if Act A exerts distinct functions at different expression levels, we sorted the stable shRNA and empty vector control clones by GFP low (shINHBA low) and GFP high (shINHBA high) expression (Figure 6a; Supplementary Figure 1). In Boyden chamber migration assays, shINHBA high and shINHBA low cells showed increased chemotactic migration compared with parent and empty vector (pGIPZh) control cells (Figure 6b; Supplementary Figure 2a). shINHBA high and shINHBA low cells showed no proliferation differences compared with controls (Supplementary Figure 2b). Interestingly, shINHBA low cells showed increased migration compared with shINHBA high cells, suggesting a dose-dependent effect of Act A signaling. Dose-dependent effects of Act A signaling have been previously described, primarily in embryogenesis. ${ }^{29-31}$ Similarly to the effect observed in the Boyden chambers, organotypic reconstructs of shINHBA high cells showed thicker epithelial cell layers and increased invasion into the underlying stroma compared with the pGIPZ high control (Figure 6c).
Finally, as we were able to observe an effect after loss of Act A in epithelial cells in vitro, we set out to explore functional consequences of Act A suppression in vivo. Utilizing a Matrigel plug xenograft model, we subcutaneously injected shINHBA high, pGIPZ high, and parent ECdnT cells with FEF into the flanks of female NOD/SCID mice. After 6 weeks of growth, mice injected with shINHBA high cells had larger tumors compared with pGIPZ high and parental control cells (Figure 6d). Therefore, we conclude that Act A function is context and concentration dependent and can either promote or inhibit epithelial cell migration, invasion, and tumor growth.

\section{DISCUSSION}

Keratinocyte differentiation in the esophagus has much in common with other squamous tissues, such as the interfollicular skin and the oropharynx, making the esophagus an outstanding model to understand squamous epithelial homeostasis and disease. ${ }^{32-34}$ We have previously shown that the coordinated loss of the cell adhesion molecule E-cadherin and $T \beta R I$ is a frequent event in esophageal squamous cell cancer and results in increased cell invasion. ${ }^{6}$ Esophageal cancer has a high mortality rate, with 5-year survival remaining static at 19\% (ref. 35) and the current treatment options for patients are restricted. The identification of mechanisms that disrupt esophageal homeostasis advances our understanding of the development and progression of preneoplastic lesions and has clinical significance.

Little is known about Act A and its involvement in esophageal disease. Act A expression is associated with lymph node metastasis, staging, poor patient prognosis, ${ }^{36}$ and concomitant upregulation of $\mathrm{N}$-cadherin. ${ }^{37}$ Act $\mathrm{A}$ has been associated with ESCC aggressiveness. This increase in aggressiveness is accompanied by increased proliferation ${ }^{16}$ and MMP-7 activity. ${ }^{38}$ We observed increased epithelial levels of MMP-9 in response to Act A stimulation, whereas MMP-2, which is mainly secreted by the fibroblasts in our system (data not shown), remained largely unaffected. Although treatment with Follistatin and A83-01 enhanced cell invasion, it results in reduced MMP-9 and MMP-2 secretion as well as activity, indicating that other mechanisms are involved in cell invasion independent of MMP-9 and MMP-2 (unpublished data). Analysis of publicly available data sets identified frequent upregulation of Act $\mathrm{A}$, but does not allow us to identify which subcellular compartment (tumor or stromal) is responsible Act A expression or secretion. Our data indicate that Act A exerts paracrine function on the fibroblasts resulting in a feedback loop required for epithelial cell invasion, as depletion of the fibroblasts in the organotypic cultures inhibits Act A-mediated cell invasion.

Our unique opportunity to analyze Act A function using three-dimensional organotypic cultures is highlighted by the differences in Act A signaling regulation as measured by its target Id1 in monolayer and three-dimensional cultures. ${ }^{23}$ Act $A$ and TGF $\beta$ overlap in their intracellular signaling 
a

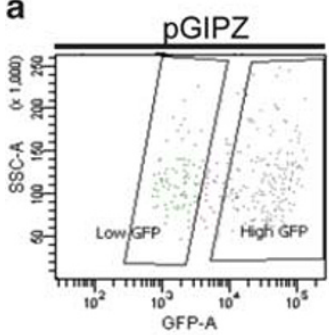

ShINHBA4

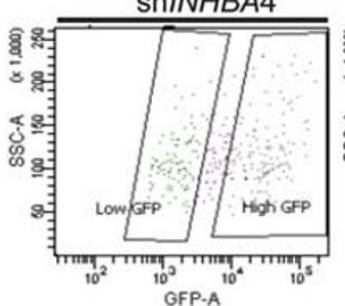

C
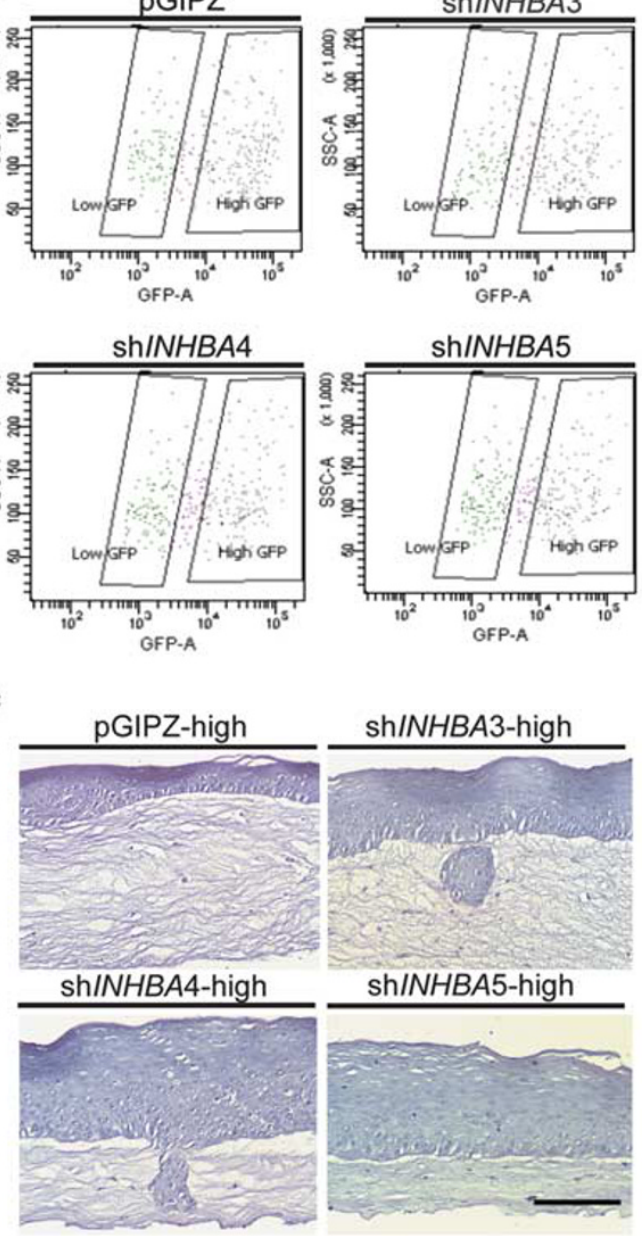

b

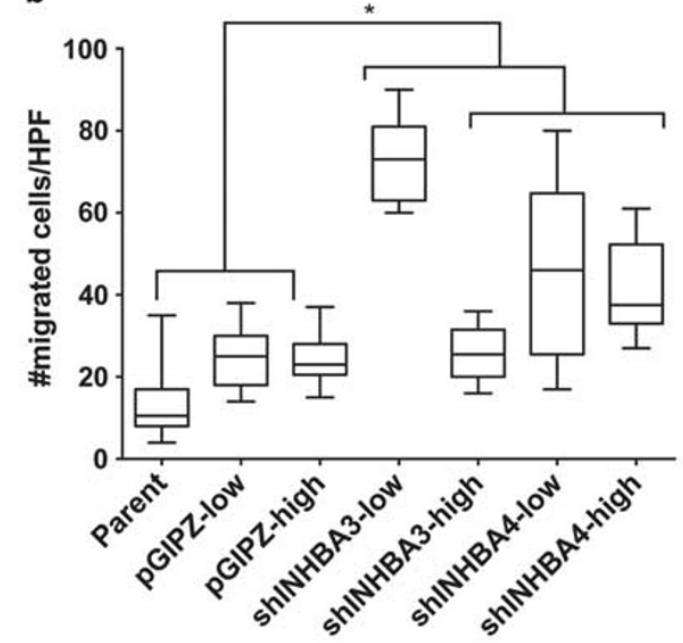

d 10

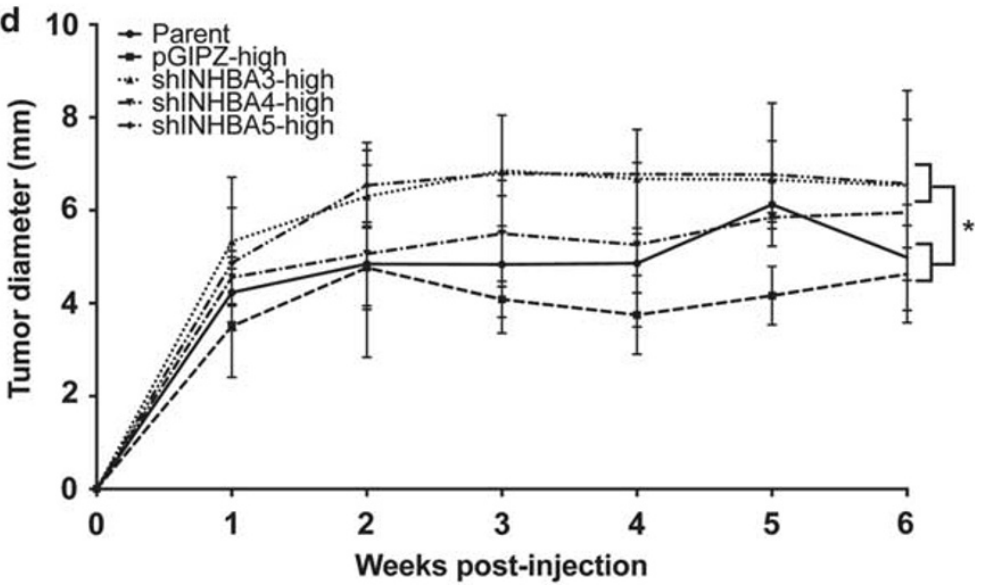

Figure 6 shRNA-mediated loss of Activin A (Act A) promotes epithelial cell migration and invasion. (a) ECdnT cells transduced with shRNA- Act A-GFP constructs (sh/NHBA3 through 5) were sorted by flow cytometry for positivity and low/high expression (left versus right gating). (b) Boyden chamber migration assays were performed using sh/NHBA high and sh/NHBA low expressing cells. Both sh/NHBA high and sh/NHBA low showed overall increased in vitro migration compared with parent and empty vector (pGIPZ high and low) cells. Migrated cells are depicted as the number of cells counted per high-powered field. Analysis was performed using a one-way ANOVA and subsequent Student's $t$-test. (c) sh/NHBA and empty vector control cells ( $p$ GIPZ high) were grown in organotypic cultures with normal fetal esophageal fibroblasts (FEF). sh/NHBA cultures had increased epithelial cell layer thickness and increased collective cell invasion into the underlying stroma, compared with control cultures. Scale bar, 50 $\mu \mathrm{m}$. (d) NOD/SCID flank injections were performed using shINHBA high and control (parent and empty vector pGIPZ high) cells, in co-culture with normal fetal esophageal fibroblasts (FEF). After 6 weeks post injection, sh/NHBA high cells showed overall greater tumor growth, compared with parent and pGIPZ high control cells.

cascades $^{24}$ and function, as demonstrated by deletions of TGF $\beta 2$, TGF $\beta 3$, and the Act A subunit, Activin $\beta_{\mathrm{A}}$, which result in cleft palate defects in the respective mouse models. ${ }^{25-28}$ Furthermore, analysis of the Act A and TGF $\beta$ induced transcriptome demonstrate multiple common downstream targets. ${ }^{39}$ Mutations in the TGF $\beta / \mathrm{BMP}$ signaling axis are frequent events in different types of cancer: Similar to a 10-bp polyadenine tract within the TGF $\beta$ receptor type II gene that results in a frameshift mutation in GI cancers, a biallelic mutation in ACVR2 has been identified in colorectal and pancreatic cancer. ${ }^{40}$ ACVR1B is mutated in pancreatic cancer. ${ }^{41}$ In a majority of sporadic colorectal cancers, BMPR2 expression is impaired. ${ }^{42}$ BAMBI (BMP and activin membranebound inhibitor) is upregulated in colorectal cancer and is under direct regulation of the Wnt pathway ${ }^{43}$ and is part of a gene expression profile that predicts metastasis. ${ }^{44}$

Interestingly, stimulation of organotypic cultures with TGF $\beta 1$ resulted in suppressed ECdnT invasion, whereas recombinant Act A was unable to inhibit cell invasion. Treatment with Act A or Act A-nAb had no effect in 'normal' organotypic epithelia retaining E-cadherin expression and intact TGF $\beta$ signaling. In these normal epithelial cells, only the addition of Follistatin induced cell invasion demonstrating the importance of a balance between the Act 
A-mediated signaling and BMP pathways. Follistatin, while binding Act A with high affinity, can also antagonize BMP signaling, in particular BMP-2, $-4,-7$, and -11 , as well as myostatin. BMPs, like Act A, signal through surface receptor complexes containing type I (ALK2 ALK3 and ALK6) and type II (BMPRII, ActRII, ActRIIB) receptors. Although the BMPs, particularly BMP-2 and BMP4, have higher affinity for their type I receptors, they can still stimulate signaling through the shared type II receptors. ${ }^{5}$ These observations indicate that changes in the balance between Act A- and BMP-mediated signaling can affect the phenotype in a context-dependent manner. ECdnT organotypic cultures, which model a premalignant phenotype, showed enhanced invasion in the presence of $\mathrm{nAb}$ and Follistatin compared with untreated cells. Although neutralizing Act A in EC cells suppressed invasion, it failed to inhibit ECdnT cell invasion indicating that more invasive cells might be less responsive to the invasion-suppressive functions of Act A. Follistatin on the other hand increased invasion in all cell lines tested.

Follistatin is an antagonist of myostatin (GDF-8) in addition to inhibiting Act A. In an analysis of publically available esophageal and head and neck squamous cell carcinoma data sets (GDS2520, GDS3838) myostatin unlike INHBA is not differentially expressed in cancer compared to normal tissues. There is no evidence in the literature that myostatin contributes to collective invasion or the initiation of ESCC, however, myostatin is a key player in later stages of cancer progression through its role in cancer cachexia. ${ }^{45,46}$

High serum levels of Follistatin have been detected in patients with ovarian ${ }^{47}$ and metastatic prostate cancer. ${ }^{48}$ In oral squamous cell carcinoma, serum levels of Follistatin and Act A were not significantly different in the tumor patients compared with control groups. ${ }^{49}$ Interestingly, Follistatin, as well as Act A, were overexpressed in tumor tissues from these patients. In the same study, Act A expression was shown to correlate with poor prognosis overall and disease-free survival, whereas Follistatin was not. ${ }^{49}$ This observation further highlights that Follistatin may have independent roles other than antagonizing Act A. In other studies, however, Follistatin upregulation has been positively correlated with cell motility, invasion and metastasis, ${ }^{50}$ whereas other groups have demonstrated that Follistatin can also inhibit experimental metastasis in SCID mice. ${ }^{51}$

Knockdown of Act A in ECdnT cells using shRNA demonstrates epithelial cell-dependent effects of Act A, whereas the response of the stromal cells remains unaltered. Furthermore, cells with low levels of Act A knockdown were more invasive than with high levels of suppression indicating a dose-dependent phenotype. As the observations for the use of $\mathrm{nAb}$ in the different cell lines appear contradictory, a possible explanation is that final Act A activity may vary following neutralization and, therefore, initiate differential cellular responses. Increased invasion and tumor initiation as observed with ECdnT cells support the notion that endogenous Act A may suppress tumor initiation. Based on mouse models targeting Act A expression in the skin, it has been shown that Act A overexpression leads to epidermal hyperplasia. ${ }^{52}$ However, when Act A-overexpressing mice were bred with transgenic animals carrying a dominantnegative deletion of the kinase-domain in the ActRIB, hyperplasia, hyperproliferation, and abnormal keratinocyte organization could be rescued. ${ }^{52}$ These data elude to the importance of Act A levels in the regulation of epithelial architecture. Interestingly, the same group observed differential results for Act A effects in vitro and in vivo, not only in regard to epithelial cell proliferation, but also migration. Act A promoted migration in the wounded skin, but showed no promigratory effect in vitro. ${ }^{52}$

These observations, along with our results, indicate that Follistatin and shRNA against Act A could increase invasion and tumorigenesis depending on the cellular context. Exogenous Act A treatment in the background of mutant T $\beta$ RII did not inhibit cell invasion, an additional hint at signal regulation through Act A gradients. Previous research regarding the role of Act $\mathrm{A}$ in embryogenesis may allow for the elucidation of the functional consequences of Act $\mathrm{A}$ during tumorigenesis, as the reactivation of essential developmental pathways have been found to contribute significantly to cancer initiation and development. Xenopus models have shown the dose-dependent effect of Act A in endomesoderm development. Act A induces specific gene expression signatures at increasing concentrations, thus inducing distinct cell fates. ${ }^{29,53-55}$ This process occurs through long-range Act A diffusion through the extracellular matrix, and has been shown to signal in a cell-specific manner. ${ }^{54,56}$ The effect of Act $\mathrm{A}$ is further complicated through its intermingling with additional signaling pathways, such as Wnt. ${ }^{57}$ Therefore, based upon our and previous studies, we conclude that the balance of Act A concentration is crucial to exert its potentially dose-dependent dual function on invasion and growth.

Of note, laser capture microdissected RNA expression analysis of invasive untreated ECdnT cells identified changes in multiple members of the TGF $\beta$ family (Supplementary Table 3). Most of these targets have been validated in mass spectrometry analysis using conditioned media from ECdnT organotypic cultures. Although BMP-2 itself was downregulated, Gremlin 1 was found to be upregulated. Similarly, the inhibitory pseudoreceptor BAMBI and latent-binding protein 1 were upregulated indicating potential $\operatorname{TGF} \beta$ signaling suppression. Further, Activin inhibitors such as Follistatin and Follistatin-like were downregulated. These observations further highlight the importance of maintaining the equilibrium between intersecting pathways in the regulation of cell invasion and potentially tumorigenesis.

In summary, we showed that overexpression and exogenous Act A treatment result in MMP-dependent invasion requiring the presence of fibroblasts. However, as Follistatin induced epithelial cell invasion and knockdown of Act A similarly resulted in enhanced cell invasion and tumorigenesis, 
we propose that low levels of Act A result in elevated motility or invasive potential, whereas high Act A levels depending on the cellular context results in less invasion. In conclusion, shifting the balance between Act A and Follistatin can disrupt epithelial homeostasis.

Supplementary Information accompanies the paper on the Laboratory Investigation website (http://www.laboratoryinvestigation.org)

\section{ACKNOWLEDGMENTS}

This work was supported by the National Institute of Health (DK94900, DK091491). The use of Research Cores is supported by the Vanderbilt Ingram Cancer Center (P30 CA68485) and the Vanderbilt Digestive Disease Research Center (P30 DK058404). We like to thank Connie Weaver for performing the Xcelligence transendothelial cell invasion assays and Rainelli B. Koumangoye for editing of the manuscript.

\section{DISCLOSURE/CONFLICT OF INTEREST}

The authors declare no conflict of interest.

1. Larsson J, Karlsson S. The role of Smad signaling in hematopoiesis. Oncogene 2005;24:5676-5692.

2. Thisse B, Wright CV, Thisse C. Activin- and nodal-related factors control antero-posterior patterning of the zebrafish embryo. Nature 2000;403:425-428.

3. Wildi $\mathrm{S}$, Kleeff J, Maruyama $\mathrm{H}$, et al. Overexpression of activin A in stage IV colorectal cancer. Gut 2001;49:409-417.

4. Harrison CA, Gray PC, Fischer $W H$, et al. An activin mutant with disrupted ALK4 binding blocks signaling via type II receptors. J Biol Chem 2004;279:28036-28044.

5. Harrison CA, Wiater E, Gray PC, et al. Modulation of activin and BMP signaling. Mol Cell Endocrinol 2004;225:19-24.

6. Andl CD, Fargnoli BB, Okawa $T$, et al. Coordinated functions of E-cadherin and transforming growth factor beta receptor II in vitro and in vivo. Cancer Res 2006;66:9878-9885.

7. Ferreira MC, Witz CA, Hammes LS, et al. Activin A increases invasiveness of endometrial cells in an in vitro model of human peritoneum. Mol Hum Reprod 2008;14:301-307.

8. Le Bras GF, Allison GL, Richards NF, et al. CD44 upregulation in E-cadherin-negative esophageal cancers results in cell invasion. PLoS One 2011;6:e27063.

9. Burdette $\mathrm{JE}$, Jeruss JS, Kurley $\mathrm{SJ}$, et al. Activin A mediates growth inhibition and cell cycle arrest through Smads in human breast cancer cells. Cancer Res 2005;65:7968-7975.

10. Danila DC, Inder WJ, Zhang X, et al. Activin effects on neoplastic proliferation of human pituitary tumors. J Clin Endocrinol Metab 2000;85:1009-1015.

11. Reis FM, Luisi S, Carneiro MM, et al. Activin, inhibin and the human breast. Mol Cell Endocrinol 2004:225:77-82.

12. Ho J, de Guise C, Kim C, et al. Activin induces hepatocyte cell growth arrest through induction of the cyclin-dependent kinase inhibitor p15INK4B and Sp1. Cell Signal 2004;16:693-701.

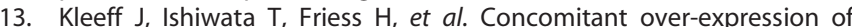
activin/inhibin beta subunits and their receptors in human pancreatic cancer. Int J Cancer 1998;77:860-868.

14. Thomas TZ, Wang H, Niclasen $\mathrm{P}$, et al. Expression and localization of activin subunits and Follistatins in tissues from men with high grade prostate cancer. J Clin Endocrinol Metab 1997:82:3851-3858.

15. Woodruff TK. Role of inhibins and activins in ovarian cancer. Cancer Treat Res 2002;107:293-302.

16. Yoshinaga K, Yamashita K, Mimori K, et al. Activin a causes cancer cell aggressiveness in esophageal squamous cell carcinoma cells. Ann Surg Oncol 2008;15:96-103.

17. Rahimi RA, Leof EB. TGF-beta signaling: a tale of two responses. J Cell Biochem 2007;102:593-608.
18. Roberts $A B$, Wakefield $L M$. The two faces of transforming growth factor beta in carcinogenesis. Proc Natl Acad Sci USA 2003;100: $8621-8623$.

19. Xiao L, Yuan $X$, Sharkis SJ. Activin A maintains self-renewal and regulates fibroblast growth factor, Wnt, and bone morphogenic protein pathways in human embryonic stem cells. Stem Cells 2006; 24:1476-1486.

20. Katoh M. Network of WNT and other regulatory signaling cascades in pluripotent stem cells and cancer stem cells. Curr Pharm Biotechnol 2011:12:160-170.

21. Lewis MT. The more things change.... the more things change: developmental plasticity of tumor-initiating mammary epithelial cells. Breast Cancer Res 2010;12:101.

22. Kowanetz $M$, Valcourt $U$, Bergstrom $R$, et al. Id 2 and Id3 define the potency of cell proliferation and differentiation responses to transforming growth factor beta and bone morphogenetic protein. Mol Cell Biol 2004;24:4241-4254.

23. Rotzer D, Krampert M, Sulyok $S$, et al. Id proteins: novel targets of activin action, which regulate epidermal homeostasis. Oncogene 2006;25:2070-2081.

24. Edgar R, Domrachev M, Lash AE. Gene Expression Omnibus: NCBI gene expression and hybridization array data repository. Nucleic Acids Res 2002;30:207-210.

25. Kupershmidt I, Su QJ, Grewal A, et al. Ontology-based meta-analysis of global collections of high-throughput public data. PLoS One 2010;29:e13066

26. Lee JJ, Natsuizaka M, Ohashi S, et al. Hypoxia activates the cyclooxygenase-2-prostaglandin E synthase axis. Carcinogenesis 2010;31: 427-434.

27. $\mathrm{Su} \mathrm{H}, \mathrm{Hu} \mathrm{N}$, Yang $\mathrm{HH}$, et al. Global gene expression profiling and validation in esophageal squamous cell carcinoma and its association with clinical phenotypes. Clin Cancer Res 2011;17: 2955-2966.

28. Eijken M, Swagemakers $\mathrm{S}$, Koedam $\mathrm{M}$, et al. The activin A-Follistatin system: potent regulator of human extracellular matrix mineralization. FASEB J 2007;21:2949-2960.

29. Symes K, Yordán C, Mercola M.. Morphological differences in Xenopus embryonic mesodermal cells are specified as an early response to distinct threshold concentrations of activin. Development 1994;120: 2339-2346.

30. Green JB, Smith JC. Graded changes in dose of a Xenopus activin A homologue elicit stepwise transitions in embryonic cell fate. Nature 1990;347:391-394

31. Green JB, New HV, Smith JC. Responses of embryonic Xenopus cells to activin and FGF are separated by multiple dose thresholds and correspond to distinct axes of the mesoderm. Cell 1992;71: 731-739.

32. Fuchs E, Horsley V. More than one way to skin. Genes Dev 2008;22: 976-985.

33. Seery JP. Stem cells of the oesophageal epithelium. J Cell Sci 2002;115:1783-1789.

34. Squier CA, Kremer MJ. Biology of oral mucosa and esophagus. J Nat Cancer Inst Monogr 2001;29:7-15.

35. Siegel R, Ma J, Zou Z, et al. Cancer statistics 2014. Cancer J Clin 2014:64:9-29.

36. Yoshinaga K, Mimori K, Yamashita K, et al. Clinical significance of the expression of activin $\mathrm{A}$ in esophageal carcinoma. Int J Oncol 2003;22:75-80

37. Yoshinaga $\mathrm{K}$, Inoue $\mathrm{H}$, Utsunomiya $\mathrm{T}$, et al. $\mathrm{N}$-cadherin is regulated by activin $A$ and associated with tumor aggressiveness in esophageal carcinoma. Clin Cancer Res 2004;10:5702-5707.

38. Yoshinaga $\mathrm{K}$, Mimori $\mathrm{K}$, Inoue $\mathrm{H}$, et al. Activin $\mathrm{A}$ enhances MMP-7 activity via the transcription factor AP-1 in an esophageal squamous cell carcinoma cell line. Int J Oncol 2008;33: 453-459.

39. Sanford LP, Ormsby I, Gittenberger-de Groot AC, et al. TGFbeta2 knockout mice have multiple developmental defects that are nonoverlapping with other TGFbeta knockout phenotypes. Development 1997;124:2659-2670.

40. Hempen PM, Zhang L, Bansal RK, et al. Evidence of selection for clones having genetic inactivation of the activin A type II receptor (ACVR2) gene in gastrointestinal cancers. Cancer Res 2003;63: 994-999. 
41. Su GH, Bansal R, Murphy KM, et al. ACVR1B (ALK4, activin receptor type 1B) gene mutations in pancreatic carcinoma. Proc Natl Acad Sci USA 2001;98:3254-3257.

42. Kodach LL, Wiercinska E, de Miranda NF, et al. The bone morphogenetic protein pathway is inactivated in the majority of sporadic colorectal cancers. Gastroenterology 2008;134:1332-1341.

43. Sekiya T, Adachi S, Kohu K, et al. Identification of BMP and activin membrane-bound inhibitor (BAMBI), an inhibitor of transforming growth factor-beta signaling, as a target of the beta-catenin pathway in colorectal tumor cells. J Biol Chem 2004;279:6840-6846.

44. Fritzmann J, Morkel M, Besser D, et al. A colorectal cancer expression profile that includes transforming growth factor beta inhibitor BAMBI predicts metastatic potential. Gastroenterology 2009;137:165-175.

45. Tisdale MJ. Mechanisms of cancer cachexia. Physiol Rev 2009;330: 171-179.

46. Massague J. TGFbeta in Cancer. Cell 2008;134:215-230.

47. Ren P, Chen FF, Liu HY, et al. High serum levels of Follistatin in patients with ovarian cancer. J Int Med Res 2012;40:877-886.

48. Tumminello FM, Badalamenti G, Fulfaro F, et al. Serum Follistatin in patients with prostate cancer metastatic to the bone. Clin Exp Metastasis 2010;27:549-555.

49. Chang KP, Kao HK, Liang $\mathrm{Y}$, et al. Overexpression of activin A in oral squamous cell carcinoma: association with poor prognosis and tumor progression. Ann Surg Oncol 2010;17:1945-1956.
50. Chen $M$, Sinha M, Luxon BA, et al. Integrin alpha6beta4 controls the expression of genes associated with cell motility, invasion, and metastasis, including S100A4/metastasin. J Biol Chem 2009;284:1484-1494.

51. Ogino H, Yano S, Kakiuchi $\mathrm{S}$, et al. Follistatin suppresses the production of experimental multiple-organ metastasis by small cell lung cancer cells in natural killer cell-depleted SCID mice. Clin Cancer Res 2008;14:660-667.

52. Bamberger C, Schärer A, Antsiferova $M$, et al. Activin controls skin morphogenesis and wound repair predominantly via stromal cells and in a concentration-dependent manner via keratinoctyes. Am J Pathol 2005; 167:733-747.

53. Saka $Y$, Smith JC. A mechanism for the sharp transition of morphogen gradient interpretation in Xenopus. BMC Dev Biol 2007; 7:4.

54. McDowell N, Gurdon JB. Activin as a morphogen in Xenopus mesoderm induction. Semin Cell Dev Biol 1999;10:311-317.

55. Gurdon JB, Harger $P$, Mitchell $A$, et al. Activin signalling and response to a morphogen gradient. Nature 1994;371:487-492.

56. Jones CM, Armes N, Smith JC. Signalling by TGF- family members: short-range effects of Xnr-2 and BMP-4 contrast with the long-range effects of activin. Curr. Biol. 1996;6:1468-1475.

57. Crease DJ, Dyson S, Gurdon JB. Cooperation between the activin and Wnt pathways in the spatial control of organizer gene expression. Proc Natl Acad Sci USA 1998;95:4398-4403. 